\title{
GAMES: ENTRETENIMENTO, MÍDIA E CULTURA
}

\author{
Games: Entertainment, media and culture
}

Juegos: Entretenimiento, medios y cultura

\author{
Valdenise Leziér Martyniuk ${ }^{1}$ \\ Mauro Maia Laruccia ${ }^{2}$
}

\section{Resumo}

Os jogos eletrônicos são um fenômeno midiático da contemporaneidade. Nesse contexto, o objetivo do artigo é dar a ver possibilidades de pesquisa e de análise, baseadas nas características desse objeto, observado em sua linguagem multimídia e sincrética. Discute-se, também, as implicações das relações promovidas entre o jogo e o jogador, bem como entre o último e outros sujeitos do entorno, resultando em interações da ordem da programação, da estratégia, da sensibilidade e do acidente. As proposições de pesquisa se ancoram na teoria semiótica de Greimas e seus seguidores e nos estudiosos do ciberespaço e das mídias audiovisuais. Os jogos, então, emergem como exemplo típico para entender a construção de sentidos no ambiente social da atualidade.

Palavras-chave: games, mídia, sincretismo, subjetividade, interação.

\begin{abstract}
Electronic games are a media contemporary phenomenon. In this context, the article purpose is to show possibilities in researches and analysis, based on these object characteristics, once it is observed at its multimediatic and syncretic language. It also discuss the consequences of the relations promoted between game and player, and among this one and other people around, resulting on interactions ordered by programation, strategy, sensibility and accident. The researches propositions are anchoraged on Greimas and his followers theories; and cyberspace and audiovisual media studiers. Games, then, emerge as typical examples to understand the meaning construction in the social environment nowadays.
\end{abstract}

\footnotetext{
${ }^{1}$ Professora Doutora dos cursos de graduação em Administração e Publicidade e Propaganda e do MBA em Marketing da Pontifícia Universidade Católica de São Paulo (PUC/SP). E-mail: valdenise@pucsp.br

2 Professor Doutor do Programa de Pós-Graduação em Comunicação e Cultura da Universidade de Sorocaba (UNISO). E-mail: mauro.laruccia@prof.uniso.br 
Keywords: games, media, sincretism, subjectivity, interaction.

\section{Resumen}

Los videojuegos son un fenómeno mediático de la contemporaneidad. En este contexto, el objetivo de este artículo es hacer conocer posibilidades de investigación y análisis, con base en las características del objeto, visto en su lenguaje multimedia y sincrético. También se analizan las implicaciones de las relaciones promovidas entre el juego y el jugador, así como entre este y los otros sujetos del entorno, dando como resultado las interacciones de la orden de la programación, la estrategia, la sensibilidad y el accidente. Las propuestas de investigación están ancladas en la teoría semiótica de Greimas y sus seguidores y en los estudiosos del ciberespacio y los medios audiovisuales. Los juegos, entonces, emergen como un ejemplo típico de entender la construcción de sentido en el entorno social de la actualidad.

Palabras-clave: juegos, medios de comunicación, el sincretismo, la subjetividad, la interacción.

\section{O CONTEXTO MERCADOLÓGICO, ECONÔMICO, CULTURAL E DE PESQUISA}

A indústria do entretenimento é grande vedete do cenário contemporâneo. Segundo dados divulgados no evento Campus Party ocorrido em janeiro e fevereiro de 2013, em São Paulo, o Brasil é um dos mercados onde a venda de games mais cresce no mundo, tanto em consoles quanto em títulos, apesar de não ter tradição na produção de jogos. O instituto de pesquisas Ibope realizou, pela primeira vez em abril e maio de 2012, uma investigação para compreender o perfil do gamer brasileiro, chegando a uma população principalmente concentrada em idade de até 19 anos e classe social B. Em outra pesquisa da consultoria PWC, chegou-se à informação de que ao menos $23 \%$ dos brasileiros joga algum tipo de game. Apesar de aparentemente grande, o número é ínfimo se comparado ao mercado americano - no Brasil $2 \%$ dos lares tem algum aparelho de videogame enquanto nos Estados Unidos esse percentual atinge 45\%, segundo a mesma empresa ${ }^{3}$.

\footnotetext{
${ }^{3}$ As pesquisas de levantamento de mercado consultadas foram realizadas pelos institutos Ibope, Ipsos, Estudos Marplan, PWC em distintos momentos do período de 2011 a 2012, abordando aspectos como atratividade do mercado brasileiro para investidores do setor, perfil descritivo dos jogadores, tamanho do
} 
Os grandes concorrentes do setor, tanto fabricantes quanto produtoras, estão ávidos por fazer emplacar suas novidades, pois, a partir da tendência de adesão dos usuários (aos consoles especialmente), resta quase que a obrigação de adquirir títulos que "rodem" na mesma tecnologia. Dentre os fabricantes, os três maiores competidores apostam nas evoluções de seus produtos na categoria de consoles: em 2013 Sony traz o lançamento do PlayStation 4; Nintendo, chega com seu Wii U e a Microsoft, com o Xbox One. Há outras versões anterioes como PS3, Wii e Xbox 360, respectivamente; soluções de mão, como o Nintendo DS (normal e 3D) e PSP. Adiciona-se a esse universo os computadores, tablets, smartphones, iPods e celulares, todos suportes possíveis para uma série interminável de games mais ou menos sofisticados.

Os títulos produzidos ocupam grande destaque na mídia especializada, ênfase comparável a que se dá ao lançamento de novidades do cinema e da televisão que prometem sucesso de público, como no exemplo: "Game de cinema - controverso GTA5 quebra recordes com produção hollywoodiana e o maior orçamento da história dos games ${ }^{4}$ ", fazendo referência aos quase trezentos milhões de dólares gastos na produção e um bilhão de dólares, em contrapartida, arrecadado nos primeiros três dias de vendas da franquia da produtora Rockstar.

A despeito dos números, que por si só demandam pesquisas quantitativas específicas e um acompanhamento periódico padronizado, já que diferentes institutos, fontes e métricas apresentam dados diversos, o que nos interessa é entender os games enquanto mídia que é espelho do contemporâneo, além de apontar algumas possíveis abordagens de pesquisa do assunto, baseadas na teoria semiótica discursiva. Nossa reflexão tratará de jogos eletrônicos (excluindo outros tipos de entretenimento, como jogos de tabuleiros e competições esportivas) o que nos deixa um grande campo de atuação, pois eles podem ser utilizados em diferentes plataformas, nas quais os modos de operação também se multiplicam. Relacionamos abaixo as mais comuns:

mercado em volumes e receita, tipos de aparatos utilizados e preferidos pelos jogadores, tempo semanal empregado em jogos, mão-de-obra disponível no Brasil, consumo de pirataria, etc. http://www.arkade.com.br/noticias/brasil-ja-4o-maior-mercado-games-mundo/, http://www.arkade.com.br/noticias/campus-party-2013-palestra-discute-desenvolvimento-games-brasil/, http://www.ibope.com.br/pt-br/conhecimento/Infograficos/Paginas/Games-pop.aspx, acesso em 19/08/13.

${ }^{4}$ Reportagem do jornal Folha de São Paulo publicada em 23 de setembro de 2013, caderno Tec, p.F6 sobe o jogo GTA5, cujo enredo gira em torno de missões seqüenciais, como episódios de uma série, protagonizadas por um dos três personagens principais (todos bandidos) a ser escolhido pelo jogador. 
- consoles conectados à televisão, manuseados por joysticks, controles remotos ou sensores de movimento;

- aparelhos celulares e smartphones, acionados por teclados ou touch screens;

- computadores pessoais, notebooks, netbooks, ultrabooks, operados por meio de mouses, teclados, joysticks ${ }^{5}$ ou touch screens;

- tablets, que além de contar com a interface touch screen, respondem por meio dos sensores de movimentação do aparato, como vibração, inclinação, etc;

Nessa visada inicial, essas modalidades serão tratadas em conjunto, mas, em uma observação posterior e pontual, seria importante delimitar mais o objeto, dada a dimensão desse universo de manifestações. O uso de diferentes aparatos de acesso é especialmente importante nesse tipo de estudo, porque a interação do jogador muda radicalmente dependendo do objeto que permite comandar suas jogadas. Consequentemente, o sentido do texto de um game se faz de modo diverso a cada procedimento, conforme veremos em exemplos adiante.

Mesmo delimitado pela característica técnica de operação, os games podem ter manifestações bastante diversificadas quanto à sua temática, desde jogos simples de ordenação de cartas disponíveis gratuitamente em qualquer computador, até os longos com roteiros complexos e produção ainda mais. Para facilitar a escolha do usuário, os games são categorizados por temas e tipos de desafios propostos ${ }^{6}$ (outra característica comum a esse gênero de texto, pois todos tem como princípio vencer um desafio):

- estratégia e de quebra-cabeças (que pedem administração de recursos e de tempo);

- ação (também chamados de arcade, exigem habilidade e velocidade de raciocínio);

- esporte e simulações (priorizam o desempenho físico, ainda que simulado);

- aventura (que implica em uma narrativa);

- $\quad$ RPG - Role Playing Game (no qual o jogador interpreta um papel);

- trivia (jogos de palavras e adivinhas).

\footnotetext{
${ }^{5}$ Os novos consoles vem equipados com joysticks que tem uma segunda tela de reprodução das imagens decorridas nos jogos.

${ }^{6} \mathrm{http} / / / \mathrm{www}$.pindoramagames.com.br/play/tipos-de-games/, acesso em 11/09/2013.
} 
Os temas e tipos de jogos elencados levam a diferentes relações inteligíveis e sensíveis na interação: entre o jogador e o jogo, do jogador consigo mesmo e do jogador com outros sujeitos. Assim, o ato de jogar não é apenas uma atividade de lazer, mas também pode implicar em sensações de conquista pessoal ou de relacionamento com uma coletividade de outros amantes de jogos. Todas essas relações podem ser ricamente analisadas com base na teoria sociossemiótica, permitindo identificar os regimes de sentido e de interação da ordem da junção e da união. As modalidades de ação, aventura e RPG, nas quais histórias se desenrolam, contam com situações que se aproximam muito das categorias narrativas do cinema: policiais, de ficção científica, do universo dos heróis infantis ou adultos, momentos dramáticos e bem humorados, etc.

A intertextualidade (com cinema, televisão, quadrinhos, brinquedos) é mais uma característica que coloca os jogos no patamar das mídias contemporâneas de destaque, com forte presença no ciberespaço e na cultura, operando como mote do relacionamento social. Tais manifestações começam a ser compreendidas pela observação das variantes e invariantes do plano de expressão, que fazem dos jogos eletrônicos um entretenimento multimídia e sincrético, o que explica parte de seu sucesso enquanto forma de entretenimento tão valiosa. A partir da semiótica greimasiana, de origem francesa e por conceitos desenvolvidos posteriormente, nos trabalhos de pesquisadores contemporâneos, temos um horizonte a percorrer para depreender o sentido que emerge dos games e das relações que projetam no social. Contamos ainda com autores que tratam dos fenômenos midiáticos da atualidade inseridos na cultura e com as discussões sobre as linguagens e a subjetividade nas mídias do ciberespaço. Amostras dessas análises são tratadas a seguir, oferecendo abertura para as possíveis investigações.

\section{MULTIMÍDIA SINCRÉTICA}

Os jogos eletrônicos já tiveram definição de imagem baixíssima, sonoridade marcada por vinhetas repetitivas e magnetizadas, diálogos (quando existiam) pífios e vazios. Atualmente, no entanto, os games tem roteiros bem mais complexos, manifestados em um sincretismo de linguagens que alcança a atração exercida no público por títulos da indústria cinematográfica. Quando à qualidade técnica, os gráficos têm chegado a simulações impressionantemente realistas. De acordo com a classificação feita por Semprini - na qual pensa sobre as marcas que se relacionam comercialmente 
com os públicos consumidores, os jogos se enquadram no tipo de mediação virtual, marcada por certas características, que podemos considerar similares às relações estabelecidas com os jogadores:

Em primeiro lugar, a forte interatividade, que a torna particularmente adaptada à construção da relação. Em segundo lugar, a dimensão espetacular e viva, advinda de sua lógica audiovisual. As técnicas de composição e de dinamismo dos sites da Internet evoluem sem cessar e permitem efeitos gráficos e formas de animação sempre mais sofisticadas. Em terceiro lugar, eles introduzem na relação uma dimensão de divertimento e de jogo que lhe dão um tom de leveza e de prazer. Enfim, ela autoriza um grau de criatividade e de participação por parte do destinatário, que pode sempre intervir ativamente em certo número de atividades ou iniciativas da marca (2006: 216).

Até mesmo os cortes entre vídeos programados e os momentos em que o jogador é chamado a interagir tornam-se leves e quase imperceptíveis, caso especialmente observado em Tomb Raider 2013 ${ }^{7}$. Nesse jogo, usando um recurso comum a outros títulos, o componente sonoro atua denunciando momentos em que a heroína Lara Croft age sozinha - em vídeos automáticos de passagem entre estágios - e outros, nos quais o jogador comanda a navegação. Ainda sobre o som, temos no jogo o uso de uma prática do cinema. A entrada e o aumento do volume do som geralmente são indicativos de perigo e sua diminuição, da suavização das ameaças que Lara enfrenta. Conforme explica Machado:

... controlando adequadamente o volume e o 'aspecto' de cada som, pode-se sugerir um certo grau de proximidade ou afastamento de cada fonte sonora em relação a um ponto (único) de escuta, configurando algo que poderia ser metaforicamente designado como uma perspectiva sonora $(2007: 112)$.

Além da perspectiva do som, podemos entender as rupturas sonoras e visuais em Tomb Raider como efeitos aspectuais de incoatividade e terminatividade, pois elas operam como mecanismos de embreagem e debreagem, convocando o jogador para agir como enunciador da próxima cena, ou afastar-se do comando, quando ocorre a entrada dos vídeos. A duratividade de uma cena ou fase, no entanto, pode variar muito, a depender do estilo e pretensões do jogador. Geralmente a descrição de um jogo traz a informação do número de horas necessárias para completar o desafio, mas alguns percorrem o seu roteiro com o objetivo de chegar o quanto antes ao final, sem procurar todos os tesouros escondidos, nem mesmo gastando tempo para ler documentos e

\footnotetext{
${ }^{7}$ Jogo observado: Tomb Raider 2013, propriedade de Square Enix Ltd., jogado em PlayStation3, operado por joystick.
} 
decifrar alguns enigmas opcionais; enquanto outro jogador se demora em cada cenário, explorando todas as possibilidades, fazendo que a experiência de jogar dure muito mais tempo.

Essa é uma característica que particulariza os jogos enquanto mídia, tanto na sua relação com o jogador, podendo ser flexível para atender um ou outro perfil, quanto quando se pensa em jogos como uma marca, grife ou potencial espaço publicitário, que, nesse atributo, teria maior sucesso junto aos jogadores que exploram mais o cenário, os recursos, os acontecimentos e, por conseguinte, seriam mais alcançados pela enunciação comercial.

Independentemente da escolha de táticas para jogar, o que essa manifestação dá a ver é uma expressão sincrética cuja combinatória depende da interação, muito mais que em outras manifestações midiáticas. Observa-se, em Tomb Raider, como descrito acima, o sincretismo das linguagens sonora e visual, aliadas a uma terceira, que poderia ser enquadrada em gestual, pois ao promover a debreagem enunciativa, mobiliza simultaneamente o som, o vídeo e faz tremular o joystick para chamar o jogador à ação. O sincretismo, na explicação de Oliveira (2009:85), pode operar por relações de reunião entre traços que se complementam, por superposição que produzem concentração, por superposição em cadeias de subordinação que geram expansão, e por paralelismo que coordenam elementos entre si. No caso do jogo observado, a operação conjunta e simultânea das linguagens, nesta debreagem enunciativa, torna a situação única e provocativa e, para produzir o efeito, opera por concentração. Mas a decisão sobre tal articulação de linguagens às vezes pode ser compartilhada com o jogador. No uso do jogo, ele pode regular volumes, usar fones de ouvido que ampliem esse sentido, pode ler ou reler um documento encontrado para considerar pistas de como decifrar um enigma e os próximos passos que irá percorrer, resultando em outras operações sincréticas diversas. Pode-se dizer então que no game o sentido se dá em ato, diante da obra e da interação do enunciatário, que convoca espaços, vídeos, textos verbais escritos, falas. Então, não temos apenas o sincretismo de linguagens, mas também um enunciador sincrético.

\section{NARRATIVAS E SUBJETIVIDADES EM JOGO}


Os roteiros dos jogos eletrônicos têm evoluído na direção de um envolvimento intenso com os jogadores. Por exemplo, no título Heavy Rain, exclusivo para plataforma Play Station, da Sony, no qual o mote é a caçada a um serial killer, o jogador pode escolher o ponto de vista de um de quatro personagens para atuar na investigação. Mesmo tipo de opção é ofertado no jogo GTA5, mencionado no início desse texto. Essa escolha pressupõe alguma identificação, em geral, muito embora a relação entre o jogador e as personagens possa se dar por vários motivos, que não necessariamente uma assumpção literal de identidade, como no caso da adoção de avatares, que não ocorre nos jogos mencionados. Machado propõe, para os objetos do ciberespaço, uma nova leitura da teoria da enunciação cinematográfica e regimes de subjetividade baseados em conceitos de imersão, navegação, narração automática, agenciamento e avatar. Sobre o últimos termo e sua relação com o jogador, o autor diz que...

\begin{abstract}
Uma outra questão que se deve considerar é até que ponto pode um avatar funcionar como o alter ego do interator. Se uma personagem é construída pelo próprio interator, se o interator a aperfeiçoa e se afeiçoa a ela, pode haver uma progressiva sintonia entre eles, a ponto de isso configurar um tipo de identificação. Por outro lado... a relação entre eles pode ser apenas técnica, o jogador tentando provar a si mesmo sua destreza e capacidade de dominar o jogo, sem uma verdadeira identificação (2007:221)."
\end{abstract}

Assim, um jogador é capaz de sentir-se envolvido emocionalmente pelo enredo e vibrantemente pelo desafio de um jogo, assumir o comando de um personagem sem, no entanto, deixar de reclamar, por exemplo, a respeito de uma falha no cenário, ou de um segredo difícil de encontrar. Apesar de assumir o papel de co-enunciador, porque de suas operações e comandos depende o destino da personagem (ao menos dentro de fases e de um macro-roteiro pré-estebelecido), o gamer reconhece a limitação desse controle e não se assume cúmplice de problemas e defeitos. Julgamento diverso fará de uma fase na qual o destino ruim de uma personagem se dê por sua falta de habilidade.

Temos então a figura de um Destinador complexo, que reúne os simulacros de várias organizações responsáveis pelos jogos e pelos equipamentos. Quando colocados na instância de enunciadores, convocam o enunciatário como co-enunciador, atribuindolhe o status de interator, denominação própria dos objetos do ciberespaço e um papel temático igualmente complexo. Machado (2007:191) comenta (citando o teórico Oliver Grau, 2003) que, embora pareça difícil para um jogador imerso em realidade virtual, distanciar-se criticamente em relação a esse conteúdo, a mesma imersão pode facilitar a 
crítica, dependendo da disposição do observador/usuário. Silva (2004:15), em reflexão sobre proposições de Edgar Morin, refuta o excesso de crítica às manifestações da mídia em geral, limitando a questão à identificação pelo imaginário:

Todas essas sociologias da manipulação tomam o telespectador, o ouvinte, o leitor, o destinatário, enfim, como imbecis culturais, seres incapazes de compreensão e de leitura crítica. Trata-se de reducionismo e de preconceito sob a máscara da crítica da alienação pela mídia. Qualquer pessoa, mesmo a mais retrógrada ou desinformada, quando vai ao cinema, é capaz de saber que se trata de cinema, ou seja, sabe separar a realidade da ficção, o possível do vivido e o espetáculo do cotidiano. Mesmo se a pessoa chora, ri, participa, ela continua ciente de que essa identificação se dá com o imaginário.

O termo "manipulação", quando empregado no excerto acima, pressupõe um destinatário passivo. Na definição dos regimes de sentido e de interação, o termo manipulação, ou estratégia, diz respeito a uma interação baseada na intencionalidade (do primeiro sujeito), mas a adesão do segundo sujeito depende de sua vontade, que pode ser mobilizada por recursos de tentação, ameaça, sedução/adulação ou provocação/desafio (LANDOWSKI: 2010).

Os jogos atuam predominantemente por esse regime, na última forma de suscitar a adesão, dado que o objeto de valor está claramente colocado no desafio que o jogo propõe e a performance do jogador está sob julgamento. Tomb Raider e outros títulos, como The Last of Us (em enredo sobre um provável apocalipse causado por uma epidemia) trazem sistemas de métricas e de avaliação do jogador, que lhe atribuem troféus de acordo com seu desempenho, simulacrado na atuação da personagem que opera. As habilidades avaliadas são nomeadas, como: caçador, sobrevivência, lutador, assassino furtivo, atirador, arqueiro, etc. Mas outra sutileza altera os critérios de avaliação: em Tomb Raider, o desempenho do jogador lhe confere pontos de habilidade e ele pode escolher, dentre várias, qual delas quer melhorar (ou comprar com seus pontos) para prosseguir nas próximas etapas. Então, além de dar mais interatividade ao jogo, a tática empregada pode diferir entre jogadores que prefiram uma ou outra habilidade mais desenvolvida.

Dessa relação, percebe-se que o game não chega a usar um avatar, tenta enquadrar o jogador nas habilidades desejadas para que as personagens atinjam desempenho superior, mas cada usuário, enquanto avança no jogo, terá uma personagem com talentos diferentes. Também não basta chegar ao final do jogo. $\mathrm{O}$ fato de não ter 
conquistado certos troféus provoca a jogar novamente para melhorar a avaliação das habilidades.

Para que se tornem mais interessantes, além da estratégia, outros regimes entram na composição narrativa. Os temas dos jogos não se limitam a situações impossíveis, caça a monstros ou guerras infindáveis com grande número de tiros ou ataques de armas diversas (embora esses sejam momentos bastante freqüentes, especialmente nos títulos de ação), mas são ambientados em realidades presentes, passadas ou cenários imaginários, nos quais as personagens vivem conflitos emocionais, morais e éticos. Em Heavy Rain, o roteiro surpreende pela emoção e dramaticidade, pois uma das principais personagens, dentre os que podem ser escolhidos pelo jogador, é o pai de uma criança sequestrada pelo assassino.

Muitas vezes o julgamento sobre como agir fica por conta do jogador, em uma projeção de identidade (que, concordando com o que os autores disseram acima, pode apenas ser uma oportunidade para que ele experimente virtualmente situações proibidas ou problemáticas na vida concreta: amigos traidores, brigas entre irmãos, famílias separadas, melindres amorosos, casos de polícia) que torna a emoção de jogar ainda mais intensa, convocando o regime de ajustamento, ancorado na competência estésica. Coloque-se um gamer em um ambiente fechado, com fones de ouvido potentes, tela enorme projetando-lhe um cenário, e um bom roteiro, e será comum vê-lo chorar, contagiado por um ser humano infectado por um zumbi ${ }^{8}$. A convocação do elemento sensível é recorrente e, nessa subjetivação, muito frequentemente, o jogo faz uso de uma personagem secundária que caminha junto a primeira, comandada pelo jogador. $\mathrm{O}$ acompanhante dialoga com o herói durante a operação do jogo, o chama, oferece orientações de caminhos, ou demonstra tédio quando este se demora demais em algum cenário, por exemplo. Ao fazer isso, por vezes encara e se dirige verbalmente ao jogador, olha para a câmera diretamente. Segundo Machado, isso seria uma transgressão na linguagem cinematográfica, na qual "o espectador do filme, portanto, jamais é interpelado diretamente pelas personagens" (2007:72).

Já vimos que os games instauram o enunciatário como co-enunciador. No pontode-vista, principalmente espacial, ele é dotado da possibilidade de manusear a câmera dentro das cenas dos jogos, explorar lugares, abrir portas. Uma das diferenças fundamentais na definição dos games diz respeito exatamente à participação do jogador

\footnotetext{
${ }^{8}$ Referência ao jogo The Last of Us.
} 
- um jogo pode ser operado em primeira ou em terceira pessoa e estas opções agradam diferentemente ao público.

Nos casos em que um herói ou heroína está presente, como Lara Croft, a operação se dá em terceira pessoa, mas o jogador pode alternar entre o manuseio da câmera, visualizando a personagem na cena, ou às vezes, assumindo o seu ponto de vista, para um salto, por exemplo, tornando a câmera subjetiva. Mas essa tomada da câmera vai ainda variar de acordo com a habilidade e destreza do jogador e com o tipo de aparato utilizado por ele - joystick, teclado, ou as próprias mãos nos jogos que contam com tecnologia mais nova de sensores de movimento. Já prevendo que o elemento sensível é chave na manutenção do interesse do jogador, Lindstrom (2005:151) analisa:

Computer games are fearlesy venturing into a whole new sensory universe via technology. Many games seek to simulate the real world... Over the next few years the computer gaming industry will push mass sensory communication even further by rolling out a variety of mice and joysticks to a world where roughly 30 percent of computer game aficionados are in front of their consoles several times a week.

Essas diferentes possibilidades apontam variações nas relações subjetivas, tendo em vista a imersão dos jogadores na narrativa. Ao dar ao jogador da possibilidade de comando e navegação, mesmo dentro de uma programação, momentos de ajustamento como os citados são freqüentes. E deles resulta boa parte do interesse e da emoção em jogar, ainda que o ajustamento seja reativo, pois é mediado pelos joysticks, principalmente. Temos também a possibilidade de ocorrência do regime de acidente. Não é incomum encontrar nos jogos defeitos de cenário, erros de programação, ou outras interrupções involuntárias, como quedas de energia, por exemplo, que inviabilizam o desenrolar de outros programas narrativos em curso.

Expandindo o ponto de vista, é importante notar que as narrativas de um game não se limitam às relações entre jogo e jogador, nem àquelas entre jogador e produtora do jogo. Talvez o dado mais interessante dessa manifestação midiática da atualidade é sua competência em agregar pessoas, criando uma rede de relações entre amigos, ou desconhecidos que apenas partilham de um interesse comum. Essa é outra grande novidade - os atuais consoles vem equipados com a possibilidade de conexão à internet, permitindo os jogos multiplayer.

Outros modos de jogar, dentro das redes sociais, já vêm embuídos do espírito colaborativo. Entram em jogo na cena enunciativa outros atores e o próprio jogador atua 
como manipulador ou entra em regime de ajustamento com outros sujeitos. Atitudes corriqueiras são, por exemplo, provocar um amigo ou desafiar outro jogador para acompanhar ou tentar ultrapassar um resultado. Na rede social, é comum receber posts como: "Oba, completei a fase 78 do Candy Crush Saga".

Apesar de ser uma frase programada, o efeito de sentido é o de contágio. Em seguida, recebe-se um convite para jogar o game com comentários do tipo: "Por favor, liberem a fase para mim", promovendo a ajuda entre amigos. Em vozes contrárias, há por exemplo a postagem de imagens de grupos familiares em suas casas, casais em restaurantes, com cada pessoa desprezando a presença física dos companheiros enquanto fala ou digita em celulares, smartphones ou tablets. Uma das imagens veio acompanhada do comentário "O dia que Einstein temia chegou: quando a tecnologia superar as relações humanas.” Essa preocupação também é manifesta por aqueles que se incomodam porque os filhos ficam muito tempo entretidos em jogos, ou porque este é seu brinquedo preferido em vez de pular corda, bater bola na rua, ou pular amarelinha desenhada com pedaços de tijolos no chão, como nos velhos tempos. As preocupações são com o eventual efeito prejudicial ao desempenho escolar, à aprendizagem e mesmo à vida social.

É fato que todos os excessos são negativos, mas algumas mudanças nos aparatos e nas práticas defendem a existência dos jogos no cenário social e midiático. Ainda que não exista o compartilhamento, a crítica aos games que tiraram as crianças do ambiente saudável das atividades físicas é rebatida com as possibilidades dos sensores de movimento, que dependem dos movimentos físicos dos jogadores para acionamento dos comandos. Os jogos mais antigos paralisavam o jogador. Os seus sucessores, na atualidade, foram capazes de reinventar o movimento (numa relação de interação sensível reativa), de reestabelecer relações entre amigos antigos ou afastados geograficamente, ou até de promover amizades à distância entre desconhecidos (uma relação de contágio). Essa faceta dos jogos que privilegia o regime do ajustamento tem sido um dos principais valores da mídia na contemporaneidade.

Outras relações externas ocorrem com blogs e revistas especializadas que comentam e detonam ${ }^{9}$ os jogos, oferecendo roteiros sobre como jogar, melhor aproveitar resultados, obter troféus, e compartilhar com os amigos suas conquistas nesse caso uma clara manifestação do regime de programação.

\footnotetext{
${ }^{9}$ Detonar é uma gíria, cujo significado é o de dar um roteiro e procedimentos para vencer as etapas de um jogo.
} 
Resumidamente, podemos constatar que existem, na relação do jogador com o game, narrativas intratextuais, da ordem do ajustamento, ancoradas na competência sensível do jogador, que reage aos impulsos sonoros, visuais, verbais, gestuais, espaciais, etc. O funcionamento do jogo consiste em uma programação, pois por mais que a navegação e o avanço de um jogador se dê em ritmo, caminhos e velocidade diferentes de outro, ambos chegarão ao mesmo destino e geralmente na mesma sequência. As relações de acidente são presentes muito frequentemente, uma vez que o ato de jogar está envolvido em meio a muitos outros acontecimentos e, portanto é passível de interferências. E todos os regimes estão articulados à relação de manipulação por provocação, ilustrada na figura do desafio. Os mesmos regimes estão em dinâmica nas relações sociais vividas a partir da presença dos jogos no universo midiático, dando margem a outras abordagens investigativas.

\section{INTERTEXTUALIDADE}

Há personagens de games que já ganharam tom de celebridade, como provam as interfaces com outras manifestações midiáticas, como os que foram adaptados para o cinema, séries de televisão, bonecos licenciados, animações. Revisitando uma vez mais Lara Croft, nascida há aproximadamente vinte anos, vemos que a personagem foi sofrendo evoluções de aparência e personalidade e migrou para o cinema na pele da atriz Angelina Jolie em dois enredos. No vídeo de lançamento do último jogo da série Tomb Raider ${ }^{10}$, destacava-se exatamente o fato de que a heroína, na nova versão, estava muito mais realista e humana. Seus seios foram reduzidos (depois de terem aumentado exagerada e impossivelmente na gradação dos episódios anteriores), suas expressões de fala e dor estavam mais presentes (enquanto que nas edições preliminares, mesmo tendo ferimentos e mortes violentas, Lara simplesmente usava um estojo de primeiros socorros, rapidamente se curava e reiniciava sua trajetória).

Do mesmo modo são realizadas por meio de intertexto as criações e recriações de games que se aproveitam de filmes, livros, séries, quadrinhos, como os hilários pássaros e porcos da série Angry Birds travestidos de personagens Star Wars, ou bonecos de Lego animados percorrendo o roteiro de Indiana Jones, com o seu característico chapéu. Mesmo destino teve Harry Potter, que nasceu nos livros, cresceu

\footnotetext{
${ }^{10}$ https://www.youtube.com/watch?v=FzhPqoKV6Lw, acesso em 15/02/2013.
} 
em fama no cinema e se aventurou nos games com impacto um pouco menor (sem contar os parques de diversão da Universal Estúdios em Orlando, Flórida, que tem no brinquedo inspirado na escola de bruxos uma de suas principais atrações).

Assim, o universo midiático e do entretenimento abarca os games e sua atual qualidade de produção tem multiplicado resultados da indústria, num círculo intertextual no qual uma produção alimenta o interesse por outra. Do ponto de vista da análise da linguagem, essas intertextualidades permitem identificar particularidades no emprego dos formantes demandadas por cada uma das mídias. Comparativamente, podem ser encontrados muitos títulos de games que, por simplesmente reproduzirem o conteúdo e a forma de outros meios, como a televisão, não alcançam interesse, qualidade e sucesso (por exemplo, a versão em jogo de Game of Trones, que é um título campeão na literatura e na televisão paga).

\section{PARA FINDAR ESSA FASE}

Os games são divertidos, emocionantes, familiares nos enredos que se aproximam dos roteiros cinematográficos, dialogam com outras mídias, são repletos de aparatos tecnológicos sedutores, contam com alta qualidade de produção, articulam linguagens de modo inteligente, sincrético e funcional, mobilizam narrativas nos vários regimes de sentido e de interação. Produzem sentido pelo sentir e pelo agir. Promovem relações de sociabilidade. Suas histórias, linguagens, estratégias de enunciação, axiologias postas em circulação, técnicas e modos de operação são elementos carregados da significação do mundo contemporâneo. Valiosos e interessantes, como prática e como objeto de estudos. E que venham adiante muitas novas etapas de pesquisa e desafios no vasto universo dos jogos eletrônicos.

\section{REFERÊNCIAS BIBLIOGRÁFICAS}

BAUMAN, Zigmund. Modernidade líquida. Rio de Janeiro: Jorge Zahar Editor, 2001.

CANDIDO, J. Campus Party 2013: palestra discute o desenvolvimento de games no Brasil. Disponível em: <http://www.arkade.com.br/campus-party-2013-palestradiscute-desenvolvimento-games-brasil/>. Acesso em: 19 ago. 2013. 
CASTELLS, Manuel. A Galáxia da Internet: reflexões sobre a internet, os negócios e a sociedade. Rio de Janeiro: Jorge Zahar Editor, 2003.

GREIMAS, Algirdas Julien e COURTÉS, Joseph. Dicionário de semiótica. Vários tradutores. São Paulo: Contexto, 2008.

IBOPE. Pesquisa Games POP. Disponível em: <http://www.ibope.com.br/ptbr/conhecimento/Infograficos/Paginas/Games-pop.aspx>. Acesso em: 19 ago. 2013.

LANDOWSKI, Eric. Interacciones arriesgadas. Lima: Universidad de Lima, Fondo Editorial, 2009.

LINDSTROM, Martin. Brand sense: sensory secrets behind the stuff we buy. New York: Free Pass, 2005.

MACHADO, Arlindo. $O$ sujeito na tela: modos de enunciação no cinema e no ciberespaço. São Paulo: Paulus, 2007.

MARTINS, Francisco Menezes; SILVA, Juremir Machado da (orgs). A Genealogia do virtual: comunicação, cultura e tecnologias do imaginário. Porto Alegre: Sulina, 2004.

OLIVEIRA, Ana Claudia de. A plástica sensível da expressão sincrética e enunciação global. In OLIVEIRA, Ana Claudia de e TEIXEIRA, Lúcia (orgs.), Linguagens na comunicação: desenvolvimentos da semiótica sincrética. São Paulo: Estação das Letras e Cores, 2009: 79-140.

ORRICO, Alexandre. Game de cinema: controverso 'GTA5' quebra recordes com produção hollywodiana e o maior orçamento da história dos games. Folha de São Paulo. São Paulo, Caderno Tec, 23 de setembro de 2013, F6.

PINDORAMA GAMES. Tipos de Games. Disponível em: <http://www.pindoramagames.com.br/play/tipos-de-games/>. Acesso em: 11 set. 2013.

PSCHEIDT, R. Brasil já é o $4^{o}$ maior mercado de games do mundo! Disponível em: <http://www.arkade.com.br/brasil-ja-4o-maior-mercado-games-mundo/>. Acesso em: 19 ago. 2013.

SEMPRINI, Andrea. A marca pós-moderna: poder e fragilidade da marca na sociedade contemporânea. São Paulo: Estação das Letras Editora, 2006. 
Games: Entretenimento, mídia e cultura

de Valdenise Leziér Martyniuk e Mauro Maia Laruccia

Tomb Raider 2013 Official Game Trailer. YouTube. Disponível em: <https://www.youtube.com/watch?v=FzhPqoKV6Lw>. Acesso em: 15 fev. 2013.

\section{JOGOS DISCUTIDOS E PLATAFORMAS}

Angry Birds Star Wars (tablet)

Candy Crush Saga (tablet e redes sociais)

Heavy Rain (PlayStation 3)

Lego Indiana Jones - the original adventure (Wii)

Paciência (PC).

The Last of Us (PlayStation 3)

Tomb Raider 2013, ou A survivor is born (PlayStation 3).

Artigo submetido: 15/04/2014

Artigo aprovado: 16/06/2015 